\title{
Vascular factors in Alzheimer's disease
}

\author{
Ivan V. Maksimovich \\ Clinic of Cardiovascular Diseases Named after Most Holy John Tobolsky, Moscow, Russia; \\ *Corresponding Author: carvasc@yandex.ru
}

Received 24 July 2012; revised 22 August 2012; accepted 31 August 2012

\section{ABSTRACT}

The vascular factor in Alzheimer's disease (AD), affecting its development and progression, is one of the most urgent problems of modern neuroangiology. The research investigates the characteristics of cerebral angioarchitectonics identified at different stages of AD. The research included 106 patients: 1) The Test Group-47 patients suffering from various stages of $A D ; 2$ ) The Control Group-59 patients suffering from the most common lesions of the brain accompanied by neurodegenerative changes, the development of dementia and cognitive impairment, but not having AD. All the patients underwent: the testing of cognitive functions (MMSE), the determination of severity of dementia (CDR) and AD stages (TDR), computed tomography (CT), magnetic resonance imaging (MRI), scintigraphy of the brain (SG), rheoencephalography (REG), and cerebral multi-gated angiography (MUGA). Patients with AD different stages showed the following changes in angioarchitectonics and microcirculation: Absence of pronounced atherosclerotic lesions of intracranial vessels, reduction of the capillary bed in the temporal and temporo-parietal regions, development of multiple arteriovenous shunts in the same areas, early venous discharge, abnormal expansion of venous trunks that receive blood from arteriovenous shunts, venous congestion at the border of the frontal and parietal region, increased looping of intracranial arteries. Control Group patients had no combination of the abovementioned changes. These vascular changes are specific for $A D$ and are in fact the vascular factor of this disease; they may also be called dyscirculatory angiopathy of Alzheimer's type (DAAT). Patients suffering from other diseases that are accompanied by neurodegenerative changes in the brain, dementia and cognitive impairment do not have them.
Keywords: Alzheimer's Disease; CDR; TDR; Dementia; Vascular Factors in Alzheimer's Disease; Dyscirculatory Angiopathy of Alzheimer's Type; DAAT

\section{INTRODUCTION}

According to the Alzheimer's Association, Alzheimer's disease (AD) is becoming a global problem of modern mankind. The number of patients suffering from this disease is increasing every year worldwide. In the United States there were 5.4 million patients in 2011 [1] and it is estimated that by 2050 the number of cases will increase to 13.5 million people [2], and in case of diagnosis and detection of preclinical stages of the disease this figure can considerably rise. In 2010, there were 35.6 million of identified cases worldwide, and by 2050 this figure is expected to increase to 115.4 million while every other inhabitant of the planet at the age of 85 and older will get sick $[1,3]$.

Active AD research began during the 1980s [4]. The introduction of CT and MRI contributed to successfully study the lifetime neurodegenerative changes that occur in the brain tissue during the development of the disease [5-7].

The use of PET and biomarkers has allowed visualizing the accumulation of amiloid-beta and tau [8-12]; however, despite the extreme perspectiveness of these studies, no standardized research methodology has been developed yet. Moreover, several authors note that in some cases high levels of these proteins are observed in practically healthy individuals not suffering from AD [11,12].

Despite the fact that the first reports of vascular changes in the brain identified in $\mathrm{AD}$ were made by $\mathrm{F}$. Morel as far back as in the 1930s [13], it was for a long time believed that vascular lesions of the brain were the cause of vascular dementia and that they had no relation to the etiology of AD [14]. Consequently, the vascular factor in $\mathrm{AD}$ was given insufficient attention. Only in recent years, the accumulation of material has promoted a research interest to this important problem [13,15-20]. The research was often conducted on experimental mod- 
els of the disease or carried out by circumstantial evidence when examining patients or based on the results of postmortem autopsies of patients with advanced $A D$ $[13,15,20]$. Lifetime angiographic studies among patients with different stages of AD have almost never been carried out.

Insufficiently researched has been the correlation of vascular and degenerative changes that develop in the brain tissue with the progression of $\mathrm{AD}$ and their joint effect on dementia and cognitive impairment [19,21,22].

The research investigates the characteristics of cerebral angioarchitectonics and defines the vascular factor in $\mathrm{AD}$ revealed at different stages of the disease.

\section{METHODS}

The whole research has been carried out with the approval of the Ethics Committee, as well as with the consent of the examined patients and their relatives.

\subsection{The Objective of This Research}

- The identification of vascular disorders developing in the brain at $\mathrm{AD}$ beginning and with its progress or, in other words, the identification of the vascular factor in $\mathrm{AD}$;

- The comparison of data obtained and cerebrovascular changes that occur among patients of the same age suffering from the most common lesions of the brain accompanied by neurodegenerative changes, the development of dementia and cognitive disorders;

- To perform a complete differential diagnosis of all the examined patients was not the objective of this research.

106 patients aged from 28 to 79 (average age 67.5) have been examined, of whom $53(50.00 \%)$ were male patients and $53(50.00 \%)$ were female patients.

\subsection{Examination of Patients}

The research plan included:

1) Cognitive function was assessed by the Mini-Mental State Examination (MMSE) [23].

2) Dementia severity was clinically determined by the Clinical Dementia Rating scale (CDR) [24].

3) AD stages were tomographically determined among Test Group patients by the Tomography Dementia Rating scale (TDR) [25] during CT and MRI examination.

4) Laboratory examination was performed according to generally accepted interventional cardiology schemes and included clinical, biochemical and coagulological examination.

5) Scintigraphy of the brain (SG) was carried out on a gamma camera (Ohio Nuclear, US) following the classical method in dynamic and static modes using TC $99 \mathrm{M}$ pertechnetate 555 .

6) Rheoencephalography (REG) was performed using "Reospektr-8" (Neurosoft, Russia) in accordance with the standard automated method determining pulse volume abnormalities in the hemispheres of the brain.

7) CT and MRI of the brain were performed on "Somatom" (Siemens), "Hi Speed" (GE), "Tomoscan" (Philips), "Apetro Eterna” (Hitachi) determining the volume of the temporal lobes of the brain followed by detection of the degree of atrophy as a percentage of total tissue weight $[19,21,22]$.

8) Cerebral multi-gated angiography (MUGA) was performed on "Advantx" (GE) following the classical method of transfemoral access. Simultaneously, taking into account the start and the speed of the injection, 10 $12 \mathrm{ml}$ of Omnipack 350 was introduced intra-carotidally and 7 - $8 \mathrm{ml}$ intra-vertebrally. Registration was carried out in direct and side projections in constant subtraction mode at a speed of 25 frames per second. Further on the angiograms obtained in each phase of contrast were analysed frame by frame [19,22]. Analysis of capillary density was performed in the appropriate phase with an automatic method by means of the computer program "Angio Vision" based on determining the degree of blackening of the corresponding image section [22,26].

\subsection{Characteristics of Patients Examined}

The test group: 47 (44.34\%) patients aged 34 to 79 (average age 67), 17 (36.17\%) male patients and 30 (63.83\%) female patients, suffered from various stages of $\mathrm{AD}$ and in accordance with the Tomography Dementia Rating scale (TDR) [25] were divided into:

- Pre-clinical AD stage-TDR-0: a group of immediate relatives of the patients who had primary involutive changes in the brain accompanied by growing memory disorders. They did not have marked symptoms of dementia or cognitive impairment, and the atrophy of the temporal lobes accounted for $4 \%-8 \%$ (MMSE score 26 - 28 points)—4 (8.51\%) patients [25,26];

- Early AD stage-TDR-1: a group with mild dementia, mild cognitive impairment, had previously been diagnosed with AD, history of the disease did not exceed 2 years, atrophy of the temporal lobes was $9 \%$ $18 \%$, which corresponds to CDR-1 (MMSE score 20 - 25 points)-15 (31.91\%) patients;

- Middle AD stage-TDR-2: a group with moderate dementia, rather persistent cognitive impairment, had previously been diagnosed with $\mathrm{AD}$, history of the disease ranged from 2 to 6 years, atrophy of the temporal lobes was $19 \%-32 \%$, which corresponds to CDR-2 (MMSE score 12 - 19 points)—20 (42.56\%) patients;

- Late AD stage-TDR-3: a group with sufficiently 
severe dementia, gross cognitive impairment, had previously been diagnosed with $\mathrm{AD}$, history of the disease ranged from 7 to 12 years, atrophy of the temporal lobes was $33 \%$ - 62\%, which corresponds to CDR-3 (MMSE score 7 - 11 points)—8 (17.02\%) patients.

The control group: 59 (55.66\%) patients aged 28 to 78 (average age 68), 36 (61.02\%) male patients and 23 (38.98\%) female patients.

Patients in this group either had different types of brain lesions accompanied by neurodegenerative changes, dementia symptoms and cognitive impairment but did not have AD, or had involutive changes of the brain but did not have any specific complaints, considered themselves healthy, and treated existing cerebral disorders as age-appropriate and normal.

These patients were divided into the following groups:

- The group with the initial stage of chronic cerebrovascular insufficiency of atherosclerotic genesis with no symptoms of persistent dementia and cognitive impairment. Typically, these patients, regardless of age, submitted individual complaints indicating cerebral hemodynamics violations-17 (28.81\%) patients, CDR-1 being observed in 6 cases;

- The group with a fairly severe chronic cerebrovascular insufficiency of atherosclerotic genesis without gross occlusive lesions of brain vessels. They had beginning mild dementia and initial cognitive impairment-12 (20.33\%) patients, CDR-1 being detected in 9 cases, CDR-2 - in 3 cases;

- The group with multiple atherosclerotic lesions of the brain, severe vascular dementia and cognitive impairment, the medical history contained recurrent small focal strokes -6 (10.17\%) patients, CDR-2 being observed in 1 case, CDR-3-in 5 cases;

- The group with atherosclerotic (vascular) parkinsonism and manifestations of dementia-14 (23.73\%) patients, CDR-1 being observed in 5 cases, CDR-2in 9 cases;

- The group with Binswanger's disease and manifestations of dementia-6 (10.17\%) patients, CDR-1 being detected in 1 case, CDR - 2-in 2 cases, CDR-3-in 3 cases;

- The group with Parkinson's disease and manifestations of dementia-4 (6.78\%) patients, CDR-1 being observed in 1 case, CDR-2-in 3 cases.

\subsection{CT \& MRI Examination}

In our previous studies [18,19,25-27] it was noted that during CT and MRI all patients suffering from AD show certain objective characteristic morphological changes of the brain which can be divided into 2 groups:

- Atrophic changes in the temporal lobes which at vari- ous stages of the disease lead to a $4 \%$ - $62 \%$ decrease in the tissue mass;

- General cerebral changes.

CT and MRI among Control Group patients revealed certain morphological changes in the brain which can be attributed to general cerebral changes; however, no specific atrophic changes in the tissue of the temporal lobes of the brain characteristic for $\mathrm{AD}$ have been identified in any case.

\section{RESULTS}

\subsection{The Test Group}

In the test group MUGA revealed the following vascular disorders (Table 1):

- Lack of (or they were poorly expressed) atherosclerotic changes of extra and intracranial arteries-47 (100\%) patients (Figures 1-5);

- Reduction of capillary phase contrast in the form of microvascular cone-shaped sites in the projection of the hippocampus and frontal-parietal regions 47 (100\%) patients (Figure 1);

- Multiple arteriovenous shunts in the basin of arterial branches supplying the fronto-parietal regions of the cerebral cortex and in the basin of the frontal villous artery supplying the hippocampus (Figure 2), accompanied by early venous discharge with simultaneous filling of arteries and veins-47 (100\%) patients ( Figure 3);

- Development of an abnormally enlarged lateral venous branches that receive blood from arteriovenous shunts in the temporal and fronto-parietal region-42 (89.3\%) patients (Figure 4);

- Abnormal venous congestion at the border of the frontal and parietal lobe-43 (91.5\%) patients (Figure 4);

- Increased looping of distal intracranial arterial branches-37 (78.72\%) patients (Figure 5).

\subsection{The Control Group}

No combination of such vascular disorders has been identified among any of Control Group patients indicating that it is specific for AD.

Control Group patients showed (Table 1):

- Atherosclerotic changes of intracranial arteries were detected in 57 (96.61\%) cases;

- Stenotic lesions of intracranial branches were detected in 45 (76.27\%) cases;

- Occlusive lesions of intracranial branches were identified in 16 (27.12\%) cases;

- Multiple scattered arteriovenous shunts at the level of the white matter of the brain were detected in 27 (45.76\%) cases; 
- Disseminated early venous dumping was detected in 28 (53.85\%) cases.

None of Test Group patients had similar disorders.

\subsection{Other Types of Examination}

During SG, there was a slowing of blood flow in the cerebral hemispheres to $\mathrm{T}_{\max } 9-13 \mathrm{sec}, \mathrm{T}_{1 / 2} 10-20 \mathrm{sec}$ observed among all patients of the test and control groups regardless of the diseases they had.

During REG, there was a $15 \%-50 \%$ decrease in the volume of pulse blood supply in the carotid basins observed among all patients of the test and control groups regardless of the diseases they had.

Table 1. Vascular disorders of the brain identified among patients of the test and control groups during MUGA.

\begin{tabular}{lccc}
\hline \multicolumn{1}{c}{ Signs } & $\begin{array}{c}\text { Test group } \\
\text { (Alzheimer's disease) }\end{array}$ & $\begin{array}{c}\text { Control group (Brain disorders } \\
\text { other than Alzheimer's disease) }\end{array}$ & p (chi-square) \\
\hline $\begin{array}{l}\text { Number of patients } \\
\text { Atherosclerotic changes }\end{array}$ & 47 & 59 & $<0.005$ \\
$\begin{array}{l}\text { Increased looping in distal regions of intracranial } \\
\text { vessels }\end{array}$ & 0 & 37 & $<0.005$ \\
$\begin{array}{l}\text { Reduction of capillary blood flow in frontopa- } \\
\text { rietal region }\end{array}$ & 47 & 0 & $<0.005$ \\
$\begin{array}{l}\text { Multiple arteriovenous shunts in frontoparietal } \\
\text { and temporal regions }\end{array}$ & 47 & 0 & $<0.005$ \\
$\begin{array}{l}\text { Multiple scattered arteriovenous shunts at the } \\
\text { level of the white substance of the brain }\end{array}$ & 0 & 27 & $<0.005$ \\
$\begin{array}{l}\text { Premature venous shunts in frontoparietal and } \\
\text { temporal regions }\end{array}$ & 47 & 0 & $<0.005$ \\
$\begin{array}{l}\text { Scattered premature venous shunts } \\
\text { Venous congestion on the boundary } \\
\text { of frontal and parietal regions }\end{array}$ & 0 & 28 & $<0.005$ \\
$\begin{array}{l}\text { Development of anomalous lateral veins in pa- } \\
\text { rietal region }\end{array}$ & 43 & 0 & $<0.005$ \\
\hline
\end{tabular}

The differences between the groups were identified by the analysis of the relevant contingency tables $2 \times 2$ by means of Pearson's chi-square test. The corresponding values of $\mathrm{p}$ are shown in the last column of the table. $\mathrm{p}$-value $=0.05$.

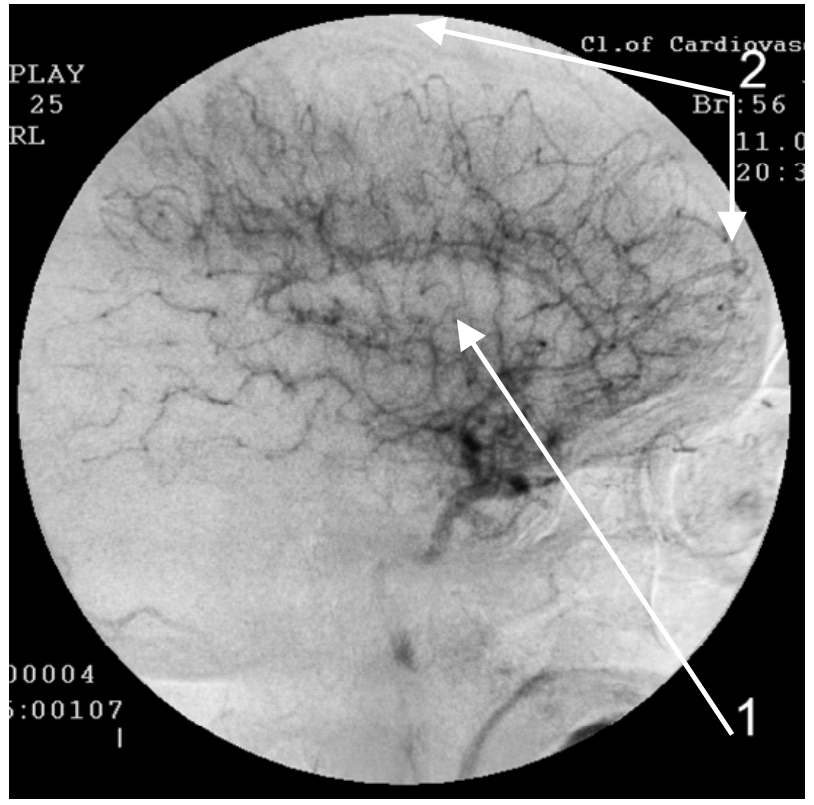

Absence of atherosclerotic changes of intracranial vessels. 1: Reduction of capillary bed in the temporal brain regions; 2: Reduction of capillary bed in the fronto-parietal brain regions.

Figure 1. Angiogram of the right internal carotid artery of patient A., 56 years old (lateral projection capillary phase), 2-year anamnesis of the disease, TDR-1.

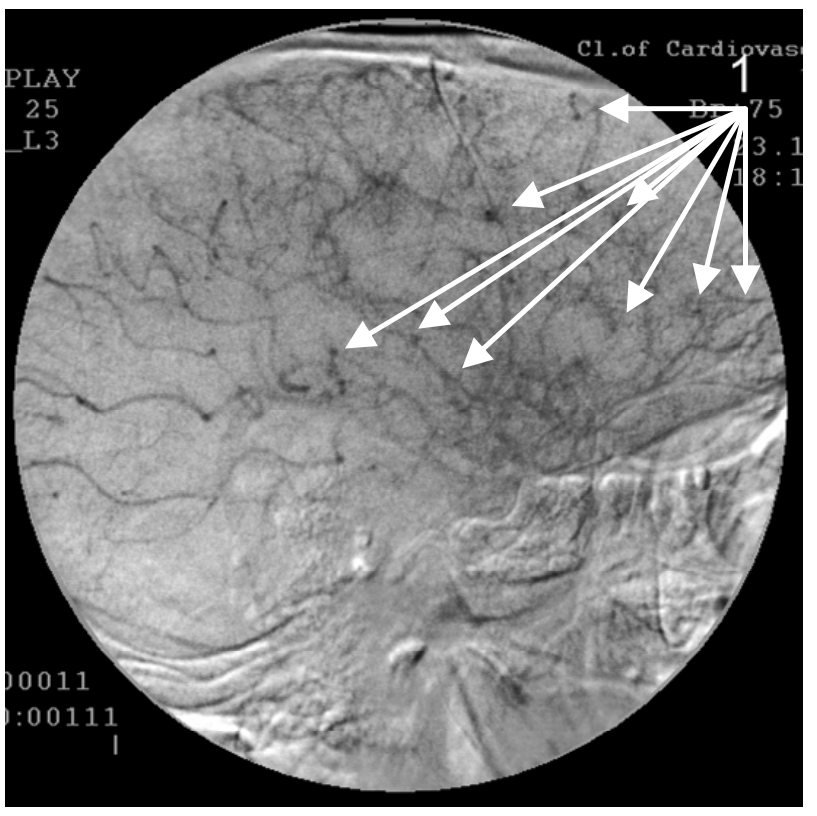

Absence of atherosclerotic changes of intracranial vessels. 1: The development of multiple arterio-venous shunts in the fronto-parietal and temporal brain regions.

Figure 2. Angiogram of the left internal carotid artery of patient P., 75 years old (lateral projection capillary phase), 12year anamnesis of the disease, TDR-3. 


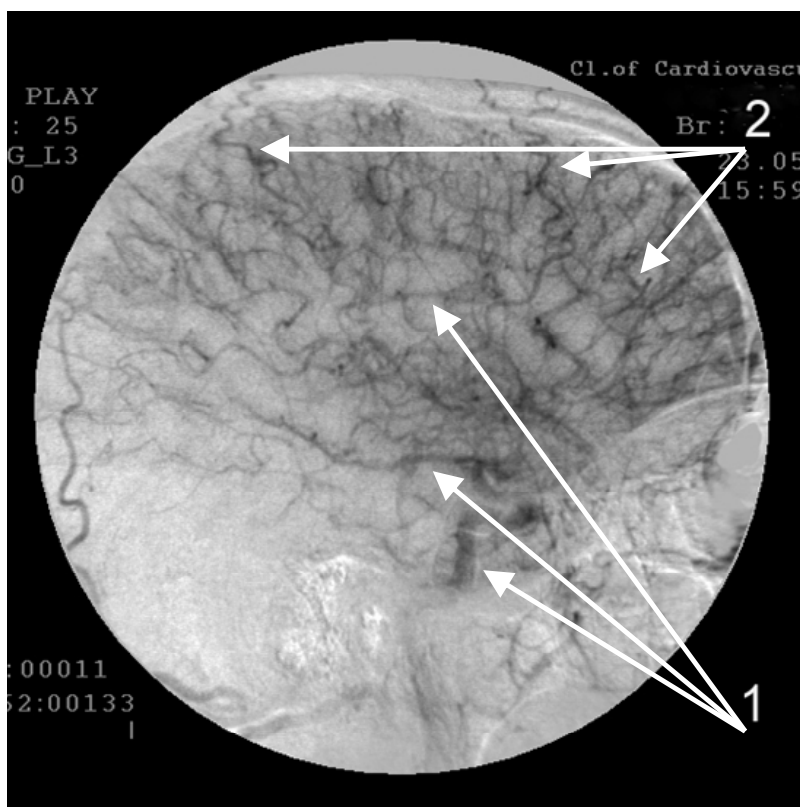

Absence of atherosclerotic changes of intracranial vessels. The development of early venous discharge in the temporal and fronto-parietal region. Simultaneous filling of arteries (1) and veins (2).

Figure 3. Angiogram of the left internal carotid artery of patient O., 72 years old (lateral projection capillary phase), 9-year anamnesis of the disease, TDR-2.

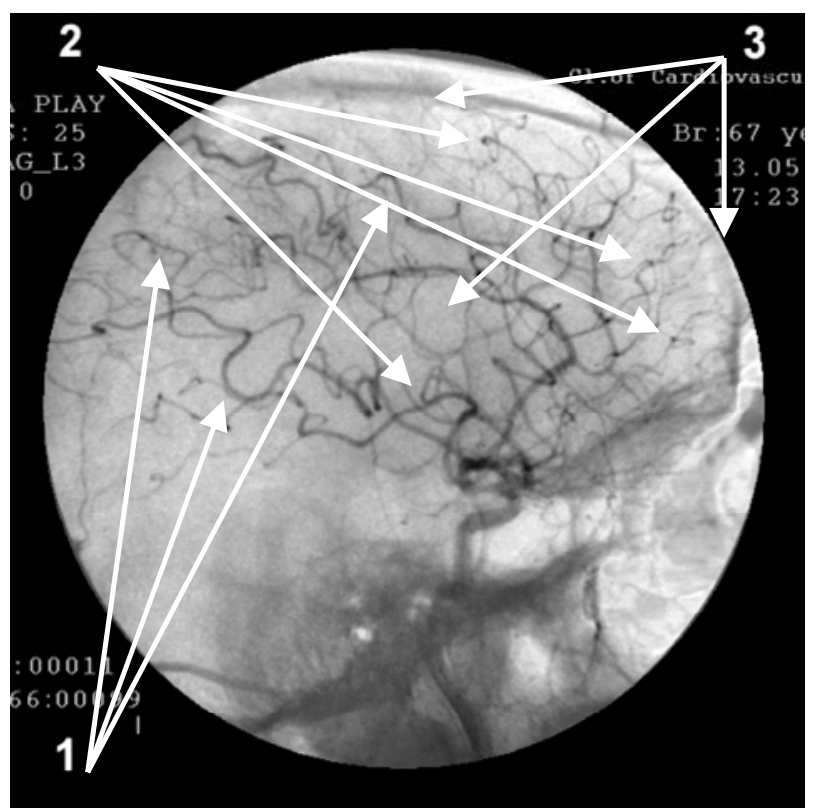

Absence of atherosclerotic changes of intracranial vessels. 1: Multiple loop formation; 2: Multiple arteriovenous shunts in fronto-parietal and temporal regions; 3: Development of hypovascular region.

Figure 5. Angiogram of the left internal carotid artery of patient S., 67 years old (lateral projection early arterial phase), 12-year anamnesis of the disease, TDR-3.

\section{DISCUSSION}

Since Control Group patients did not have the specific

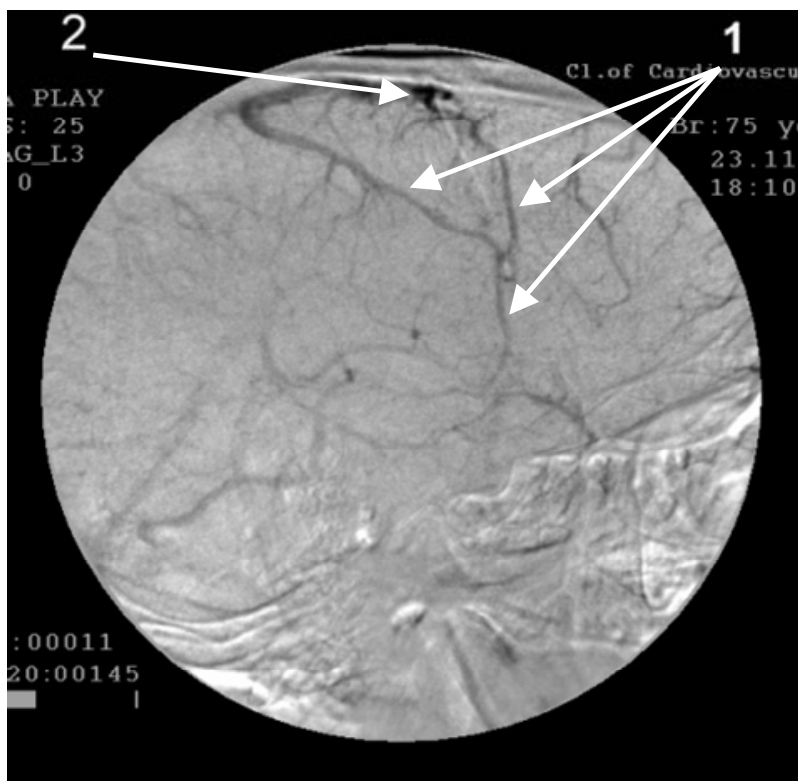

Absence of atherosclerotic changes of intracranial vessels. 1: The development of pathologically enlarged veins that receive blood from arterio-venous shunts in the temporal and fronto-parietal region; 2: Blood stagnation on the border of the fronto-parietal region.

Figure 4. Angiogram of the left internal carotid artery of patient P., 75 years old (lateral projection venous phase), 12 year anamnesis of the disease, TDR-3.

blood supply and microcirculation disorders in the temporal and fronto-parietal brain regions identified among Test Group patients, we can conclude that these disorders are specific for $\mathrm{AD}$ and are not specific for other diseases associated with the development of neurodegenerative changes in the brain burdened by the development of dementia and cognitive disorders. It suggests that these vascular changes are the vascular factor in $\mathrm{AD}$ [15-17, 20,28,29]. We have also called these changes the "dyscirculatory angiopathy of Alzheimer's type” (DAAT) [18, 19,27].

The severity of these disorders does not depend on how fast AD symptoms develop or how severe dementia is, they are almost equally observed among patients with pre-clinical (TDR-0) and clinical (TDR-1, TDR-2, TDR3 ) stages of the disease and are not only the vascular factor but also the vascular symptom of AD [25].

The essence of the vascular factor in $\operatorname{AD}[18,19,26]$ is the reduction of the capillary bed in the temporal and fronto-parietal regions of the brain which in turn leads to the formation of multiple arteriovenous shunts in these areas. The developed arteriovenous shunts lead to early arteriovenous blood dumping resulting in the development of abnormally enlarged venous trunks that receive blood from the temporal and fronto-parietal region, which in turn leads to venous congestion at the border of the frontal and parietal lobes [18,27].

Disorders of microcirculation in the brain identified 
among patients suffering from $\mathrm{AD}$ are described by many authors $[16,17,30]$.

However, the vascular factor includes not only capillary but also distal arterial and venous disorders. Obviously, these changes lead to a breach in hemodynamics and cause specific hypoxia in these areas, which in turn may contribute to slower excretion and increased accumulation of amyloid-beta in the walls of blood vessels, paravasal tissue and the tissue of the temporal and fronto-parietal brain regions, which in turn contribute to $\mathrm{AD}$ development and progress [31]. These data are confirmed by other authors [32] showing that AD development in the brain tissue is accompanied by the accumulation of vasculotoxic and neurotoxic molecules causing a decrease in cerebral blood flow and hypoxia which in turn lead to the development of dysfunction and neurodegenerative changes.

It cannot be said with absolute certainty that vascular disorders are directly related to the early deposition of amyloid-beta in the capillary and arterial wall or paravasal tissue [26]. Moreover, it is unlikely that such accumulation of amyloid-beta occurs well before the onset of symptoms. It should be noted that there are studies showing that vascular changes in the temporal lobes of the brain are detected even among AD patients' children and grandchildren [33]. As a result, the question of what comes first arises: is it the vascular factor manifested in congenital or acquired disorders of blood flow and microcirculation of the brain that promotes the development of $\mathrm{AD}$ [18] or is it the disease itself that causes similar changes in distal arterial, microcirculatory and venous bed $[26,29]$. This question has recently been the issue of concern to many authors, but no definite answer has been found yet [34].

The severity of the disease, the severity of dementia and cognitive impairment, the state of higher mental functions are frequently directly dependent on the severity of atrophic changes in the brain tissue [19,35-38]. Thus, patients with pre-clinical TDR-0 stage have $4-8 \%$ atrophy of the temporal lobes, but patients with advanced TDR-3 AD stage have 33\% - 62\% atrophy [19,21,22,27], though vascular disorders occurring in the brain during the development of $\mathrm{AD}$ are at about the same level among all patients regardless of their TDR group [21,27].

The combination of these structural and vascular disorders is specific for the development of $\mathrm{AD}$ and is not found among patients suffering from other neurodegenerative diseases of the brain accompanied by the development of dementia and cognitive impairment $[18,27]$. The significance of vascular disorders is confirmed by other authors [16,38-40].

Thus, it can be concluded that the vascular factor which plays an important role at the beginning and development of $\mathrm{AD}$ and is represented by dyscirculatory angiopathy of Alzheimer's type (DAAT) is shown in:

- The reduction of the capillary bed in the temporal and fronto-parietal brain regions;

- The development of multiple arteriovenous shunts in the same regions;

- Early venous shunts in the same regions;

- The development of abnormally enlarged venous trunks receiving blood from arterial-venous shunts in the temporal and fronto-parietal brain regions;

- The stagnation of venous blood on the border of the frontal and parietal regions;

- Large looping of distal branches of intracranial arteries.

These changes can be traced among patients with both advanced and preclinical stages of the disease and are not only the vascular factor but also the vascular symptoms of $\mathrm{AD}$. At the same time, $\mathrm{AD}$ patients have either none or poorly expressed atherosclerotic changes of intracranial vessels.

The vascular factor in $\mathrm{AD}$ is of great importance as it is necessary to develop a new effective treatment for this disease.

\section{REFERENCES}

[1] Alzheimer's Association (2011) Alzheimer's disease facts and figures. http://www.alz.org/downloads/Facts_Figures_2011.pdf

[2] Alzheimer's Association (2010) Alzheimer's disease facts and figures.

http://www.alz.org/documents_custom/report_alzfactsfig ures2010.pdf

[3] Generation Alzheimer's: The defining disease of the baby boomers.

http://act.alz.org/site/DocServer/ALZ_BoomersReport.pd f?docID $=521$

[4] Torack, R.M. (1979) Adult dementia: History, biopsy, pathology. Neurosurgery, 4, 434-442. http://www.ncbi.nlm.nih.gov/pubmed/379682

[5] Saykin, A.J. and Wishart, H.A. (2003) Mild cognitive impairment: Conceptual issues and structural and functional brain correlates. Seminars in clinical. Neuropsychiatry, 8, 12-30.

http://www.ncbi.nlm.nih.gov/pubmed/12567329

[6] Shen, L., Fipri, H.A., Saykin, A.J. and West, J.D. (2009) Parametric surface modeling and registration for comparison of manual and automated segmentation of the hippocampus. Hippocampus, 19, 588-595.

http://www.ncbi.nlm.nih.gov/pubmed?term=Parametric\% 20surface\%20modeling\%20and\%20registration\%20for\% 20comparison\%20of\%20manual\%20and\%20automated\% 20segmentation\%20of\%20the

[7] Waldemar, G., Dubois, B., Emre, M., et al. (2007) Recommendations for the diagnosis and management of Alzheimer's disease and other disorders associated with dementia: EFNS guideline. European Journal of Neuro- 
$\log y$, 14, e1-e26. http://www.ncbi.nlm.nih.gov/pubmed/17222085

[8] Perrin, R.J., Craig-Schapiro, R., Morris, J.C., et al. (2011) Identification and validation of novelcerebrospinal fluid biomarkers for staging early Alzheimer's disease. Public Library of Science One, 12, e16032.

http://www.ncbi.nlm.nih.gov/pmc/articles/PMC3020224/ ?tool=pmcentrez

[9] Trojanowski, J.Q., Vandeerstichele, H., Korecka, M., et al. (2010) Update on the biomarker core of the Alzheimer's disease neuroimaging initiative subjects. Alzheimer's \& Dementia, 6, 230-238. http://www.ncbi.nlm.nih.gov/pubmed/20451871

[10] Adriaase, A., Sanz-Arigita, E., Binnewijzend, M., et al. (2011) Molecular markers of Alzheimer's disease pathology and their relationship with default mode network integrity. Alzheimer's \& Dementia, 7, S2-S3.

http://www.alzheimersanddementia.com/article/S1552-52 60(11)00144-0/fulltext

[11] Chételat, G., Villemagne, V.L., Pike K.E., Ellis, K.A., Ames, D., Masters, C.L. and Rowe, C.C. (2012) Relationship between memory performance and $\beta$-amyloid deposition at different stages of Alzheimer's disease. Neurodegenerative Diseases, 10, 141-144. http://www.ncbi.nlm.nih.gov/pubmed/22301812

[12] Meyer, P.T., Hellwig, S., Amtage, F., et al. (2011) Dualbiomarker imaging of regional cerebral amyloid load and neuronal activity in dementia with PET and 11C-labeled Pittsburgh compound B. Journal of Nuclear Medicine, 52, 393-400. http://www.ncbi.nlm.nih.gov/pubmed/21321269

[13] Morel, F. (1950) An apparently dyshoric and topical angiopathy. Monatsschrift für Psychiatrie und Neurologie, 120, 352-357. http://www.ncbi.nlm.nih.gov/pubmed/14806299

[14] Di Carlo, A., Baldereschi, M., Amaducci, L., et al. (2002) Incidence of dementia, Alzheimer's disease, and vascular dementia in Italy. The ILSA study. Journal of the American Geriatrics Society, 50, 41-48.

http://www.ncbi.nlm.nih.gov/pubmed?term=Di\%20Carlo \%2C\%20A.\%20Baldereschi\%2C\%20M.\%20Amaducci\% 2C\%20L.\%20et\%20all.\%20(2002).\%20Incidence\%20of \%20dementia\%2C\%20Alzheimer's\%20disease\%2C\%20a nd\%20vascular\%20dementia\%20in\%20Italy.\%20The\%2 0ILSA\%20Study.

[15] Skoog, I., Kalaria, R.N. and Breteler, M.M. (1999) Vascular factors and Alzheimer disease. Alzheimer Disease and Associated Disorders, 13, 106-114.

http://www.ncbi.nlm.nih.gov/pubmed?term=Skoog\%20I \%2C\%20Kalaria\%20R\%20N\%2C\%20Breteler\%20M.M.

[16] Kalaria, R.N. (2002) Small vessel disease and Alzheimer's dementia: Pathological considerations. Cerebrovascular Diseases, 13, 48-52. http://www.ncbi.nlm.nih.gov/pubmed/11901243

[17] Kalaria, R.N. (2003) Vascular factors in Alzheimer's disease. International Psychogeriatrics, 15, 47-52. http://www.ncbi.nlm.nih.gov/pubmed/16191216

[18] Maksimovich, I.V. (2009) Changes in angioarchetectonics of brain at Alzheimer's disease. The Neurologic Bulletin,
2, 9-14.

http://www.infamed.com/nb/2_2009_9-14.pdf

[19] Maksimovich, I.V. (2010) Dyscirculatory angiopathy of the brain of Alzheimer's type. Alzheimer's \& Dementia, $\mathbf{6}$, 34-35.

http://www.alzheimersanddementia.com/article/S1552-52 60(10)02300-9/fulltext

[20] Altman, R. and Rutledge, J.C. (2010) The vascular contribution to Alzheimer's disease. Clinical Science, 119, 407-421.

http://www.ncbi.nlm.nih.gov/pmc/articles/PMC2950620/ ?tool=pubmed

[21] Maksimovich, I.V. and Gotman, L.N. (2006) Method of complex radiation diagnostics at preclinical and clinical stages of Alzheimer's disease. Russian Patent No. 2315559. http://bankpatentov.ru/node/28577

[22] Maksimovich, I.V., Gotman, L.N. and Masyuk, S.M. (2006) Method of determining dimensions of temporal brain lobes in patients suffering from Alzheimer's disease. Russian Patent No. 2306102.

http://worldwide.espacenet.com/publicationDetails/biblio ?DB=EPODOC\&adjacent $=$ true\&locale $=$ en_EP\&FT $=\mathrm{D} \&$ date $=20070920 \& C C=$ RU \&NR $=2306102 C 1 \& \mathrm{KC}=\mathrm{C} 1$

[23] Folstein, M.F.S., Folstein, S.E. and McHugh, P.R. (1975) Mini-mental state. A practical method for grading the cognitive state of patients for the clinician. Journal of Psychiatric Research, 12, 189-198.

http://www.ncbi.nlm.nih.gov/pubmed?term=Folstein\%2C \%20M.F.\%20S.\%20Folstein\%2C\%20S.\%20E.\%20McHu gh\%2C\%20P.R.\%20Mini-mental\%20state\%E2\%80\%9D. \%20A\%20practical\%20method\%20for\%20grading\%20th e\%20cognitive\%20state\%20of\%20patients\%20for\%20th e\%20clinician

[24] Morris, J.C. (1993) The clinical dementia rating (CDR): Current version and scoring rules. Neurology, 11, 24122414. http://www.ncbi.nlm.nih.gov/pubmed/8232972

[25] Maksimovich, I.V. (2012) The tomography dementia rating scale-Morphologicalli determined scale of Alzheimer's disease stages. Journal of Alzheimer's Disease, 8, 335-336.

http://www.alzheimersanddementia.com/article/S1552-52 60(12)01059-X/fulltext

[26] Maksimovich, I.V. (2011) Endovascular low-energy laser radiation effect on dyscirculatory angiopathy of Alzheimer's type in the treatment of Alzheimer's disease. Alzheimer's \& Dementia, 7, S791-S793.

http://www.alzheimersanddementia.com/article/S1552-52 60(11)02427-7/fulltext

[27] Maksimovich, I.V. (2011) Dyscirculatory angiopathy of Alzheimer's type. Journal of Behavioral and Brain Science, 1, 57-68.

http://www.google.com.hk/search?gcx=c\&sourceid=chro me\&ie=UTF-8\&q=doi\%3A10.4236\%2Fhealth.2012.4291 10

[28] Chen, W., Song, X., Beyea, S., D’Arcy, R. and Zhan, Y. (2011) Rockwood K advances in perfusion magnetic resonance imaging in Alzheimer's disease. Alzheimer's \& Dementia, 7, 185-196.

http://www.ncbi.nlm.nih.gov/pubmed/21074500 
[29] Rodriguez, G., Vitali, P., Calvini, P., Bordoni, C., Girtler, N., Taddei, G., Mariani, G. and Nobili, F. (2000) Hippocampal perfusion in mild Alzheimer's disease. Psychiatry Research, 100, 65-74. http://www.ncbi.nlm.nih.gov/pubmed/11114492

[30] Hunter, J.M., Kwan, J., Malek-Ahmadi, M., Maarouf, C.L., Kokjohn, T.A., Belden, C., Sabbagh, M.N., Beach, T.G. and Roher, A.E. (2012) Morphological and pathological evolution of the brain microcirculation in aging and Alzheimer's disease. PLoS One, 7, e36893. http://www.ncbi.nlm.nih.gov/pubmed?term=\%5B30\%5D \%09Hunter\%2C\%20J.\%20M.\%20Kwan\%2C\%20J\%20\% 20Malek-Ahmadi\%2C\%20M.\%20Maarouf\%2C\%20C.\% 20L.\%20Kokjohn\%2C\%20T.\%20A.\%20Belden\%2C\%20 C.\%20Sabbagh\%2C\%20M.\%20N.\%20Beach\%2C\%20T. G.\%20Roher\%2C\%20A.\%20E.\%20(2012)\%20Morpholo $\mathrm{g}$

[31] Weller, R.O., Subash, M., Preston, S.D., Mazanti, I. and Carare, R.O. (2008) Perivascular drainage of amyloidbeta peptides from the brain and its failure in cerebral amyloid angiopathy and Alzheimer's disease. Brain $\mathrm{Pa}$ thology, 18, 253-266.

http://www.ncbi.nlm.nih.gov/pubmed/18363936

[32] Zlokovic, B.V. (2011) Neurovascular pathways to neurodegeneration in Alzheimer's disease and other disorders. Nature Reviews Neuroscience, 3, 723-738.

http://www.ncbi.nlm.nih.gov/pubmed?term=Zlokovic\%2 C\%20B.\%20V.\%20(2011)\%20Neurovascular\%20pathwa ys\%20to\%20neurodegeneration\%20in\%20Alzheimer's\% 20disease\%20and\%20other\%20disorders.\%20

[33] Maksimovich, I.V. and Polyaev, Yu. A. (2010) The importance of early diagnosis of dyscircular angiopathy of Alzheimer's type in the study of heredity of Alzheimer's disease. Alzheimer's \& Dementia, 6, e43. http://download.journals.elsevierhealth.com/pdfs/journals 1552-5260/PIIS1552526010023253.pdf

[34] Cameron, D.J., Galvin, C., Alkam, T., Sidhu, H., Ellison, J., Luna, S. and Ethell, D.W. (2012) Alzheimer's related peptide amyloid- $\beta$ plays a conserved role in angiogenesis. PLoS One, 7, e39598.

http://www.ncbi.nlm.nih.gov/pubmed?term=Alzheimer'sRlated\%20Peptide\%20Amyloid-\%CE\%B2\%20Plays\%20 a\%20Conserved\%20Role\%20in\%20Angiogenesis
[35] Chiang, G.C., Insel, Ph.S., Tosun, D., Schuff, N., TruranSacrey, D., Raptentsetsang, S., Jack, C.R. and Weiner, M.W. (2011) Identifying cognitively healthy elderly individuals with subsequent memory decline by using automated MR temporoparietal volumes. Radiology, 259, 844-851. http://www.ncbi.nlm.nih.gov/pubmed/21467255

[36] Dickerson, B.C. (2006) Functional magnetic resonance imaging of cholinergic modulation in mild cognitive impairment. Current Opinion in Psychiatry, 19, 299-306. http://www.nmr.mgh.harvard.edu/ bradd/dickerson_curro pnpsych_2006.pdf

[37] Tae, W.S., Kim, S.S., Lee, K.U., et al. (2008) Validation of hippocampal volumes measured usinga a manual method and two automated methods (free surfer and IBASPM) in chronic major depressive disorder. Neuroradiology, 50, 569-581. http://www.ncbi.nlm.nih.gov/pubmed/18414838

[38] Burton, E.J., Barber, R., Mukaetova-Ladinska, E.B., Robson, J., Perry, R.H., Jaros, E., Kalaria, R.N. and O’Brien, T.J. (2009) Medial temporal lobe atrophy on MRI differentiates Alzheimer's disease from dementia with Lewy bodies and vascular cognitive impairment: A prospective study with pathological verification of diagnosis. Brain, 132, 195-203.

http://www.ncbi.nlm.nih.gov/pubmed?term=\%5B37\%5D \%09Burton\%2C\%20E.J.\%20Barber\%2C\%20R.\%20Muk atova-Ladinska\%2C\%20E.B.\%20Robson\%2C\%20J.\%20 Perry\%2C\%20R.H.\%20Jaros\%2C\%20E.\%20Kalaria\%2C \%20R.\%20N.\%20O'Brien\%2C\%20T.\%20J.\%20(2009)\% 20Medial\%20temporal\%20lobe\%20atrop

[39] Hommet, C., Mondon, K., Constans, T., Beaufils, E., Desmidt, T., Camus, V. and Cottier, J.P. (2011) Review of cerebral microangiopathy and Alzheimer's disease: Relation between white matter hyperintensities and microbleeds. Dementia and Geriatric Cognitive Disorders, 32, 367-378. http://www.ncbi.nlm.nih.gov/pubmed/22301385

[40] De la Torre, J.C. (2012) A turning point for Alzheimer's disease? Biofactors, 38, 78-83.

http://www.ncbi.nlm.nih.gov/pubmed?term=De\%20la\%2 0Torre\%20J.\%20C.\%20(2012)\%20A\%20turning\%20poin t\%20for\%20Alzheimer's\%20disease $\% 3 F$ 